\title{
(2) OPEN ACCESS \\ Combined use of a Total Control Introducer and a hyperangulated video laryngoscope to place a left- sided double lumen endotracheal tube in a patient with a history of difficult laryngoscopy
}

\author{
Jacob E Pollard, D Warner Smith, David E Morgan, John D Skaggs
}

Anesthesiology, University of Utah Health Hospitals and Clinics, Salt Lake City, Utah, USA

\section{Correspondence to}

Dr Jacob E Pollard;

Jacob.Pollard@hsc.utah.edu

Accepted 2 September 2021

Check for updates

(c) BMJ Publishing Group Limited 2021. Re-use permitted under CC BY-NC. No commercial re-use. See rights and permissions. Published by BMJ.

To cite: Pollard JE, Smith DW, Morgan DE, et al. BMJ Case Rep 2021;14:e243407. doi:10.1136/bcr-2021243407

\section{SUMMARY}

We describe the use of a Total Control Introducer (TCI) in combination with video laryngoscopy (VL) to place a left-sided double-lumen endotracheal tube (DLT) in a patient with a history of difficult laryngoscopy undergoing video-assisted thoracoscopic surgery (VATS). $V L$ was used to obtain visualisation of the glottis and a $\mathrm{TCl}$ articulating introducer was used to dynamically navigate the airway and access the trachea. A 39 French DLT was subsequently passed over the $\mathrm{TCI}$ shaft and into the trachea under indirect visualisation. The $\mathrm{TCl}$ shaft was removed and the DLT was gently guided into the left main bronchus. Successful endobronchial intubation was confirmed with capnography, auscultation and fibreoptic bronchoscopy. We propose that the combined use of $\mathrm{VL}$ and a $\mathrm{TCl}$ can facilitate placement of a DLT in a patient with a known difficult airway who may otherwise be limited to a bronchial blocker placement for lung isolation during VATS.

\section{BACKGROUND}

Management of the difficult airway can be one of the most stressful situations encountered by the anaesthesia provider. Safely securing a difficult airway not only requires a high degree of skill, but it often demands a significant amount of time and resources. In procedures requiring lung isolation and single-lung ventilation (SLV), such as videoassisted thoracoscopic surgery (VATS), the difficult airway presents a special challenge. SLV is typically accomplished by endobronchial intubation using a double-lumen endotracheal tube (DLT), or by bronchial blocker (BB) placement through a single-lumen endotracheal tube (SLT). During VATS procedures, a DLT is the preferred method of lung isolation; however, DLT placement can be particularly difficult in the patient with a history of difficult laryngoscopy. ${ }^{1}$

Using video laryngoscopy (VL) for glottic visualisation, we report rapid and safe placement of a 39 French left-sided DLT in a patient with a known history of difficult laryngoscopy using a novel articulating introducer called the Total Control Introducer (TCI); TTCmed.com, Salt Lake City, Utah, USA).

\section{CASE PRESENTATION}

A 67-year-old man with adenocarcinoma of the right upper lobe presented for VATS and right upper lobectomy. Medical history was remarkable for heavy tobacco use. Airway exam revealed a Mallampati II airway, a thyromental distance $>3 \mathrm{~cm}$, adequate mouth opening and normal neck extension. Of note, the patient was taken to the operating room two times on the same day: the first time electively and the second time emergently.

During the elective case, the patient was connected to American Society of Anesthesiologists (ASA) monitors and was preoxygenated with 100\% oxygen via face mask connected to a closed circuit. Induction of anaesthesia consisted of intravenous midazolam, fentanyl, lidocaine, propofol and rocuronium. After induction, an oropharyngeal airway was placed, and bag-mask ventilation (BMV) was initiated to deliver oxygen and isoflurane until achieving a train-of-four ratio of $0 / 4$ twitches. The first attempt at laryngoscopy was performed with a Macintosh 3.5 blade and resulted in a CormackLehane (CL) grade IV view. The second attempt at laryngoscopy was performed with a Miller 2 blade yielding a CL Grade III view. At this point, a 39 French left-sided DLT was placed blindly by the attending anaesthesiologist. Correct placement was confirmed via auscultation, capnography and fibreoptic bronchoscopy (FOB). After the procedure, the patient was successfully extubated and transported to the intensive care unit.

Later that day, the patient returned emergently to the operating room for evacuation of a haemothorax with the on-call anaesthesia team. With the recent history of difficult laryngoscopy, the on-call team decided to manage the patient's airway with VL and a TCI for left sided DLT placement. After monitor placement and preoxygenation as above, the patient was induced with lidocaine, fentanyl, propofol and rocuronium. After induction of anaesthesia, an oropharyngeal airway was placed, and BMV was initiated to deliver oxygen and isoflurane until a train-of-four ratio of $0 / 4$ twitches was achieved. Laryngoscopy was performed using video laryngoscope (Glidescope; Verathon; Bothel, Washington, USA) with a hyperangulated Macintosh four blade yielding a 100\% percentage of glottic opening score. A TCI was guided alongside the laryngoscope under direct visualisation until the tip was visible in the VL field of view. Under indirect visualisation, the tip of the TCI was dynamically navigated through the vocal cords and into the trachea. The TCI handle was removed leaving only the TCI shaft 
in place. Through the bronchial lumen, a 39 French left-sided DLT was then passed over the TCI through the glottic opening and into the trachea. The TCI shaft was removed and the DLT was gently guided into the left main bronchus. Correct placement was confirmed via auscultation, capnography and FOB. At the end of the procedure, the patient was extubated and returned to the intensive care unit.

\section{TREATMENT}

See body of text for airway management.

\section{OUTCOME AND FOLLOW-UP}

At the end of the procedure, the patient was extubated and was safely returned to the intensive care unit. The patient had no further complications during his hospital stay and did not require any additional operative management.

\section{DISCUSSION}

A DLT is the preferred method for lung isolation during VATS for multiple reasons. A DLT allows for easy placement, rapid deflation and inflation of the operative lung, bilateral inspection using FOB, lung sequestration from bleeding/infection and the ability to apply CPAP to the operative lung during periods of hypoxaemia. ${ }^{2}$ Under most circumstances, a left-sided DLT is a reasonable and appropriate option. Left DLT placement is typically performed under direct laryngoscopy (DL). Once the DLT tip and bronchial cuff pass through the glottic opening, the stylet is removed, and the tube is rotated counterclockwise as it is gently directed into the left main bronchus. ${ }^{3}$ Confirmation of correct placement is verified using lung auscultation, capnography and FOB. ${ }^{4}$ Due to both the large size and the required rotation after passage through the glottic opening, DLT placement can be challenging in a patient with a history of a difficult intubation or laryngoscopy.

Although challenging, there are many ways to safely place a DLT in the patient with a difficult airway. The preoperative airway exam and the predicted ease of BMV after induction of general anaesthesia should be considered when choosing a particular technique. For example, in the case of known or suspected difficult laryngoscopy or intubation, it is appropriate to secure the airway with an SLT using awake FOB. After induction of anaesthesia, the SLT can either be exchanged for a DLT, or a BB can be placed to achieve lung isolation. ${ }^{56}$ Likewise, in a situation of unanticipated difficult laryngoscopy or intubation, an SLT can be placed using FOB or VL, followed by tube exchange or $\mathrm{BB}$ placement. Multiple case reports describe additional techniques for DLT placement after induction of general anaesthesia. These include the use of a preloaded DLT on a fibreoptic bronchoscope and traditional VL. ${ }^{7-9}$ There is even a report of DLT placement using lighted stylet. ${ }^{10}$

Studies have shown that VL provides an improved view of the glottis compared with DL in patients with both normal and difficult airways. ${ }^{11}{ }^{12}$ However, in spite of improved glottic visualisation, there is no guarantee of successful intubation. For example, intubation failure in a large study using VL was often attributed to problems with endotracheal tube (ETT) advancement despite an excellent view of the glottis. ${ }^{13}$ This phenomenon is attributed to the serpentine pathway that must be navigated through the oropharynx and into the trachea when using VL. Greenland, et al described this pathway as being comprised of two curves: a primary oropharyngeal curve

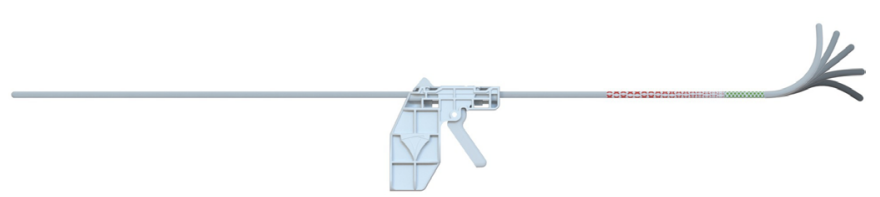

Figure 1 The Total Control Introducer is a novel articulating introducer without optical capability. Engaging the pistol grip, the user can articulate the introducer tip anteriorly and posteriorly for dynamic navigation through a patient's airway. The distal end of the shaft has colour coded depth bands that provide visual feedback to the user regarding the depth of the introducer in the trachea. Once appropriately positioned, the pistol grip can be removed, allowing pass over of an endotracheal tube. If desired, an endotracheal tube can be preloaded behind the pistol grip prior to laryngoscopy.

and a secondary pharyngo-glotto-tracheal curve. ${ }^{14}$ During DL, these curves are aligned facilitating ETT advancement; however, during VL these curves remain intact resulting in the need to first navigate in an anterior direction (oropharyngeal curve) followed by a posterior direction (pharyngoglotto-tracheal curve). Typical rigid or malleable stylets have no dynamic navigation ability making precise navigation of the serpentine path potentially difficult or impossible.

Bougies, malleable stylets or precurved rigid stylets in widespread use are designed for navigation of the anterior (oropharyngeal) curve only. These devices rely on the anterior tracheal tissue to redirect the ETT into the correct position within trachea. Some introducers with dynamic tips (Flex Tip Bougie and RPiS Stylet) have a fixed anterior curve built into the distal shaft that cannot be articulated posteriorly. Thus, any force used to advance an ETT over these introducers into the trachea likewise risks injury to anterior tracheal tissue. Not surprisingly, a recent study demonstrated increased anterior tracheal tissue injury when rigid stylets were used with $\mathrm{VL}$ as opposed to no stylet. ${ }^{15}$

One method to overcome the challenge of airway navigation is combining the use of VL with FOB. Multiple studies have demonstrated this 'combined technique' to facilitate intubation of the difficult airway. ${ }^{17}{ }^{17}$ In this scenario, VL is used to achieve visualisation of the glottis and FOB is used to navigate through the oropharynx and into the trachea. The TCI has been used in a similar manner to intubate a patient with a known difficult airway and a patient with an airway

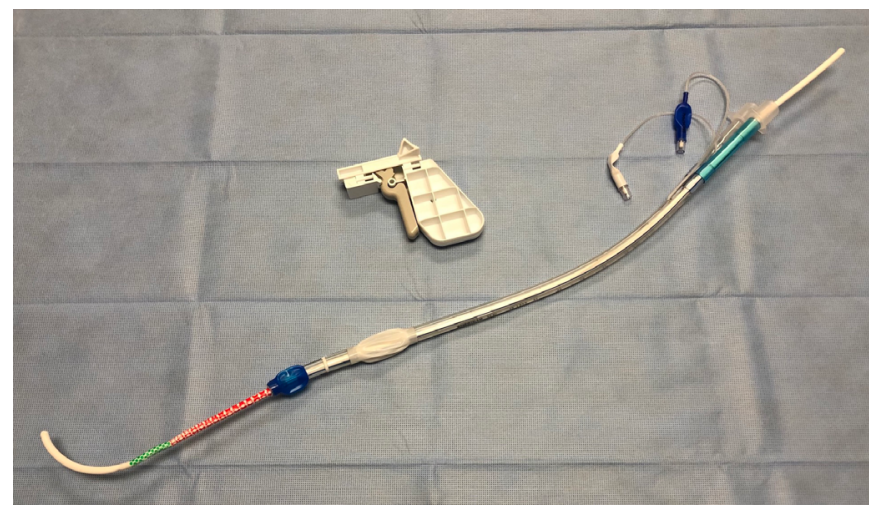

Figure 2 With lubrication, the Total Control Introducer (TCI) can accommodate pass over through the bronchial lumen of a 37 French double lumen endotracheal tube (and larger). Shown in the photo is the $\mathrm{TCl}$ shaft through the bronchial lumen of a 37 French left sided double lumen tube. Also seen in the picture is the removable pistol grip. 


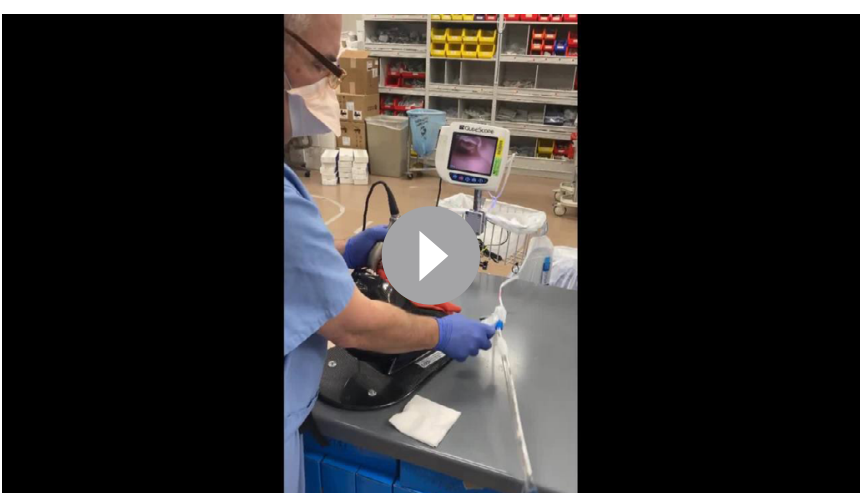

Video 1 Placement of a left-sided dlt in an airway mannequin is demonstrated using a Total Control Introducer (TCl) and video laryngoscopy (VL). A 39 French left-sided dlt is preloaded onto the $\mathrm{TCl}$ through the bronchial lumen. A view of the Glottis is achieved using VL and the $\mathrm{TCl}$ is appropriately articulated to navigate into the trachea. The pistol grip handle is removed, and the double-lumen endotracheal tube (DLT) is passed over the $\mathrm{TCl}$ shaft under indirect visualisation through the glottic opening. The $\mathrm{TCl}$ is removed, and the DLT is guided into the left main bronchus.

tumour. ${ }^{18}{ }^{19}$ Nasotracheal intubation has also been reported using VL and a $\mathrm{TCI}^{20}{ }^{20} \mathrm{~A}$ recently published case series also demonstrated the TCI as a rescue tool after failed VL or DL. ${ }^{21}$

The TCI is a 15 French, $70 \mathrm{~cm}$ long novel articulating introducer that provides dynamic user control via tip anteflexion and retroflexion using a removable pistol grip. In conjunction with VL, the user can navigate the upper airway and access the trachea under indirect visualisation. The shaft of the TCI is flexible enough to atraumatically navigate airway curvature, yet stiff enough to accommodate pass-over of an ETT. Well lubricated, the TCI shaft can accommodate pass-over of a 6.0 SLT and a 37 French DLT (through the bronchial lumen). Figure 1 shows a standard TCI and figure 2 shows a TCI through the bronchial lumen of a 37 French DLT. (See video 1 clip showing left-sided DLT placement on an airway mannequin.)

Use of the TCI begins with acquiring a view of the glottic opening using VL. Engaging the pistol-grip, the TCI tip is straightened and advanced under direct visualisation alongside

\section{Learning points}

- The airway is made up of two curvatures: a primary curvature from the oropharynx to the glottic opening, and a secondary curvature from the glottic opening into the trachea.

- Visualisation of the glottis with a hyperangulated video laryngoscope maintains the primary and secondary curves of the airway creating a serpentine pathway to the trachea. This serpentine pathway can sometimes make tracheal access difficult or impossible despite an adequate percentage of glottic opening view during video laryngoscopy.

- Placement of a double-lumen endotracheal tube (DLT) is preferred during video-assisted thoracoscopic surgery procedures, but can be particularly difficult in a patient with a history of difficult intubation or laryngoscopy.

- Using video laryngoscopy, a DLT can be rapidly and safely placed using and articulating stylet, like the Total Control Introducer, in a patient with a difficult airway. the laryngoscope blade until it is seen in the VL field of view. At this point, the TCI tip is articulated anteriorly to reach the glottic opening. It is then articulated posteriorly and advanced between the vocal cords into trachea. Tracheal depth is gauged by aligning the vocal cords adjacent to the green markings on the distal TCI shaft. The pistol grip is removed and an ETT is passed over the TCI through the vocal cords and into the trachea. The TCI shaft is then removed leaving the ETT in place. With minimal assistance, the entire procedure can be performed under indirect visualisation.

In conclusion, we report the first use of a TCI to place a 39 French left-sided DLT in a patient with a history of difficult laryngoscopy. Combining the superior view of VL along with the dynamic manoeuvrability of a TCI may allow for DLT placement in difficult airway situations in which lung isolation is required. Further studies are needed to fully understand the potential benefit in this context.

Contributors JEP: conceptualisation, writing-original draft preparation, visualisation. DWS: writing- reviewing and editing, validation. DEM: writingreviewing and editing, validation. JDS: writing-reviewing and editing, validation.

Funding The authors have not declared a specific grant for this research from any funding agency in the public, commercial or not-for-profit sectors.

Competing interests None declared.

Patient consent for publication Consent obtained directly from patient(s). Provenance and peer review Not commissioned; externally peer reviewed.

Open access This is an open access article distributed in accordance with the Creative Commons Attribution Non Commercial (CC BY-NC 4.0) license, which permits others to distribute, remix, adapt, build upon this work non-commercially, and license their derivative works on different terms, provided the original work is properly cited and the use is non-commercial. See: http://creativecommons.org/ licenses/by-nc/4.0/

\section{REFERENCES}

1 Brodsky JB, Cohen E. Video-Assisted thoracoscopic surgery. Curr Opin Anaesthesiol 2000;13:41-5.

2 Zhao Z-R, Lau RWH, Ng CSH. Anaesthesiology for uniportal VATS: double lumen, single lumen and tubeless. J Vis Surg 2017:3:108.

3 Boucek CD, Landreneau R, Freeman JA, et al. A comparison of techniques for placement of double-lumen endobronchial tubes. J Clin Anesth 1998; 10:557-60.

4 SMITH GB, HIRSCH NP, EHRENWERTH J. Placement of double-lumen endobronchial tubes. Br J Anaesth 1986;58:1317-20.

5 Campos JH. Lung isolation techniques for patients with difficult airway. Curr Opin Anaesthesiol 2010;23:12-17.

6 Thota RS. Conversion of a single lumen tube to double lumen tube in an anticipated difficult airway: flexible fiberoptic bronchoscope assisted with intubating introducerguided technique. Ann Card Anaesth 2016;19:149.

7 Bein B, Caliebe D, Römer T, et al. Using the Bonfils intubation fiberscope with a double-lumen tracheal tube. Anesthesiology 2005;102:1290-1. doi:10.1097/00000542-200506000-00042

8 Hernandez AA, Wong DH. Using a Glidescope for intubation with a double lumen endotracheal tube. Can J Anaesth 2005:52:658-9.

9 Chen A, Lai H-Y, Lin P-C, et al. GlideScope-assisted double-lumen endobronchial tube placement in a patient with an unanticipated difficult airway. J Cardiothorac Vasc Anesth 2008;22:170-2.

10 Scanzillo MA, Shulman MS. Lighted stylet for placement of a double-lumen endobronchial tube. Anesth Analg 1995;81:205-6.

11 Kaplan MB, Hagberg CA, Ward DS, et al. Comparison of direct and video-assisted views of the larynx during routine intubation. J Clin Anesth 2006;18:357-62.

12 Griesdale DEG, Liu D, McKinney J, et al. Glidescope ${ }^{\circledR}$ video-laryngoscopy versus direct laryngoscopy for endotracheal intubation: a systematic review and meta-analysis. Can J Anaesth 2012;59:41-52-52.

13 Kleine-Brueggeney $M$, Greif R, Schoettker $P$, et al. Evaluation of six videolaryngoscopes in 720 patients with a simulated difficult airway: a multicentre randomized controlled trial. Br J Anaesth 2016;116:670-9.

14 Greenland KB, Edwards MJ, Hutton NJ, et al. Changes in airway configuration with different head and neck positions using magnetic resonance imaging of normal airways: a new concept with possible clinical applications. Br J Anaesth 2010;105:683-90.

15 Yoon $\mathrm{H}-\mathrm{K}$, Lee H-C, Oh H, et al. Postoperative sore throat and subglottic injury after McGrath $\circledast$ MAC videolaryngoscopic intubation with versus without a stylet in 
patients with a high Mallampati score: a randomized controlled trial. BMC Anesthesiol 2019;19:137.

16 Sanfilippo F, Sgalambro F, Chiaramonte G, et al. Use of a combined LaryngoBronchoscopy approach in difficult airways management: a pilot simulation study. Turk J Anaesthesiol Reanim 2019;47:464-70.

17 Mazzinari G, Rovira L, Henao L, et al. Effect of dynamic versus Stylet-Guided intubation on First-Attempt success in difficult airways undergoing Glidescope laryngoscopy: a randomized controlled trial. Anesth Analg 2019:128:1264-71.

18 Pollard J, Runnels S, Warrick C. First case report of intubation with a total control introducer and a Hyperangulated video laryngoscope. A A Pract 2020;14:e01310.
19 Keefe K, Cannon R, Runnels S. Successful intubation of a patient with a supraglottic tumor using a novel Articulating introducer for precision tracheal access. Journal of Head and Neck Anesthesia;in press. doi:10.1097/ hn9.0000000000000031

20 Kumar A, Gupta N, Kumar V, et al. Total control introducer-aided nasotracheal intubation using a videolaryngoscope in an anticipated difficult airway: a novel technique. BMJ Case Rep 2020;13:e236118.

21 Shah A, Durnford K, Knecht $\mathrm{L}$, et al. A consecutive case series of rescue Intubations with the Articulating total control introducer for precision tracheal access. A A Pract 2021;15:e01418.

Copyright 2021 BMJ Publishing Group. All rights reserved. For permission to reuse any of this content visit https://www.bmj.com/company/products-services/rights-and-licensing/permissions/

BMJ Case Report Fellows may re-use this article for personal use and teaching without any further permission.

Become a Fellow of BMJ Case Reports today and you can:

- Submit as many cases as you like

- Enjoy fast sympathetic peer review and rapid publication of accepted articles

- Access all the published articles

- Re-use any of the published material for personal use and teaching without further permission

Customer Service

If you have any further queries about your subscription, please contact our customer services team on +44 (0) 2071111105 or via email at support@bmj.com.

Visit casereports.bmj.com for more articles like this and to become a Fellow 